\title{
The Structural Annotations of The Mir-122 Non-Coding RNA from The Tilapia Fish (Oreochromis niloticus)
}

\author{
Arli Aditya Parikesit ${ }^{1 *}$, Imron Imron ${ }^{2 *}$, Rizky Nurdiansyah ${ }^{1}$, David Agustriawan ${ }^{1}$ \\ ${ }^{1}$ Department of Bioinformatics, School of Life Sciences, Indonesia International Institute for Life Sciences, Jakarta, Indonesia \\ ${ }^{2}$ Research Institute for Fish Breeding, Subang, Indonesia
}

ARTICLE INFO

Article history:

Received April 21, 2021

Received in revised form September 27, 2021

Accepted October 11, 2021

KEYWORDS:

tilapia,

Oreochromis niloticus,

miRNA,

transcriptomics,

RNAcentral,

molecular modeling,

\begin{abstract}
Tilapia (Oreochromis niloticus) is an important fisheries commodity. Scientific efforts have been done to increase its quality. One of them is staging a premium diet such as a fat-enriched diet. The transcriptomics approach is able to provide the signatures of the diet outcomes by observing the micro(mi)RNA signature in transcriptional regulation. Hence, it was found that the availability of mir-122 is essential in the regulation of a high-fat diet in tilapia. However, this transcriptomics signature is lacking structural annotations and the complete interaction annotations with its silencing(si)RNA. RNAcentral website was navigated for the latest annotation of mir-122 from tilapia and other species as a comparison. MEGA X was employed to comprehend the miRNA evolutionary repertoire. The RNA secondary structure prediction tools from the Vienna RNA package and the RNA tertiary structure prediction tools from simRNA and modeRNA are secured with default parameters. The HNADOCK tools were leveraged to observe the interaction between mir-122 and its siRNA. The post-processing was conducted with the Chimera visualization tool. The secondary and tertiary structure of the mir-122 and its siRNA could be elucidated, docked, and visualized. In this end, further effort to develop a comprehensive molecular breeding tool could be secured with the structural annotation information.
\end{abstract}

\section{Introduction}

Tilapia fish, or Oreochromis niloticus, is considered an important aquaculture product worldwide that originated from Africa and spread into more than 90 countries (De Silva et al. 2004). As it could live in a temperature range of 8 to $42^{\circ} \mathrm{C}$ in freshwater and hot spring, tropical countries such as Southeast Asia could serve as their habitat (FAO 2019a). It was projected that Tilapia fish production already reaching 6.3 million tonnes, and south-east Asian countries will play an important part there (FAO 2019b). The breeding techniques of Tilapia fish are not considered complicated. They may be carried out in the aquaponic system as well as in pond-based or hapa-based breeding systems (Bhujel et al. 2001; Fessehaye et al. 2006; Storey 2017). As male Tilapia significantly make more profit due to its bigger size and less time or energy for breeding. Various

\footnotetext{
* Corresponding Author

E-mail Address: arli.parikesit@i31.ac.id
}

techniques such as methyltestosterone and YY super male were generated to breed male-only offspring (Towers 2013). In this respect, with the advance of molecular biology, more sophisticated techniques were introduced as breeding molecular markers based on genomics and proteomics technology. There are currently molecular markers categorized into cytoplasmic, dominant, and codominant types, and the most common molecular markers in use are based on mitochondrial (mt)DNA and simple sequence repeat (SSR) signatures (Amoussou et al. 2019). Moreover, sex-specific DNA markers have already been developed for facilitating the production of the genetically male Tilapia with different determination loci (Chen et al. 2018). A more specific molecular marker, such as Prolactin I microsatellite, has been developed with satisfactory performance to assist breeding (Chi 2014).

However, it is already known that the transcriptomics approach could eventually detect the activities of the genes that are beyond the coverage of the genomics and proteomics-based 
technology (Dong and Chen 2013). In this regard, transcriptomics-based markers are already widely utilized for molecular medicine and agriculture research (Parikesit et al. 2017; Anurogo et al. 2019). Moreover, aquatic-based biomarkers have been developed for fish breeding as well (Collí-Dulá et al. 2016). Bioinformatics has played important role in developing the transcriptomics markers with specialized machine-learning-based tools (Parikesit 2018b). Molecular modeling and simulation-based approaches such as RNA structure elucidation and molecular docking methods are widely utilized to annotate the transcriptomics biomarkers (Parikesit 2018a). Chou in Chou (2004) stated that the current approach in biomarkers development always considers bioinformatics tools in assisting the wet laboratory efforts. The important biomarker that is currently becoming a focal point in transcriptomics development is the non-coding(nc)RNA (Mattick 2005). ncRNA is gaining importance because ncRNA could become a viable alternative toward the standard proteomics one (Amaral and Mattick 2008). One of the important types of small ncRNA is micro(mi)RNA, which is approximately 22 base pair long and explicitly inhibit gene function (Kozomara and Griffiths-Jones 2011). miRNA plays an important role in various metabolic and physiological functions of the organism such as the immune system, digestive pathway, and neurological function (Griffiths-Jones 2006). Another type of small ncRNA that is very similar to miRNA is the silencing(si)RNA or the interference RNA (RNAi). The difference between both types is the biogenesis of miRNA involves the unwinding process, while the siRNA involves the cleavage process. Moreover, both of them have a distinct secondary structure (Ui-Tei 2016). The interesting part is the availability of siRNA to inhibit miRNA activities could trigger developmental defects in various organisms (Chapman et al. 2004). Moreover, artificial miRNA has already been utilized as siRNA expression vector for human disease, and this is a strong argument that actually there is a feasible interaction between miRNA and siRNA (Boudreau et al. 2009). In this end, the utilization of siRNA is crucial because it is already proven be able to knock down genes and transcripts that are responsible for human and animal disease.

In this regard, in order to provide more biomarkers alternatives for fish breeding, a specific transcriptomics approach should be devised for Tilapia fish markers (Li et al. 2015). Moreover, as one of the problems of Tilapia's breeding is their inclination towards a high-fat diet, a specific biomarker should be leveraged. Hence, it is found that high-fat diets in Tilapia will induce the upregulation of mir-122 transcriptomics-based biomarkers that are highly correlated with lipid metabolism and fat deposition (Qiang et al. 2018). Moreover, mir-122 also plays an important role in regulating stress response (Qiang et al. 2017). Although the metabolic pathway of the mir-122 has already been elucidated, its structural annotations are still not determined yet due to the inherent difficulty in RNA crystallography experiment (Holbrook and Kim 1997; KE 2004; Reyes et al. 2009). The absence of structural information may hamper the development of more fine-grained biomarkers in the future. The information on the interaction between mir-122 of Tilapia with other biomarkers is also absent because the database for ncRNA in animals is currently unavailable (Bonnici et al. 2018). Thus, in this end, the objective of this research is to determine the in silico structural annotations of the mir-122 Tilapia biomarker in order to shed light on its molecular interactions. It is expected that the elucidated structure will pave the way to find more information about the fish breeding transcriptomics-based pathway, especially their molecular interactions.

\section{Materials and Methods}

The pipeline for this experiment was developed based upon previous venues that have been improved significantly (Parikesit and Anurogo 2018; Parikesit et al. 2018). The computer used is a MacBook Pro ${ }^{\circledR}$ Laptop (13-inch, Late 2011) with 16 GB RAM, Intel HD Graphics $3000 \AA$, and 500 GB SATA disk for securing good performance in molecular computation (Cense 1989; Baro and Hughes 1991; Smith 1995; Oliver et al. 2019). The pipeline is mainly comprised of two parts, namely the sequence and structural analyses.

\subsection{Sequence Analysis}

The first step would be retrieving mir-122 sequences from RNAcentral database with respect to representative species of Mus musculus, Bos Taurus, Danio rerio, Oreochromis niloticus (Tilapia fish), Xenopus tropicalis, Homo sapiens, and Gallus gallus that inspired from UCSC genome browser annotated genomes(Speiretal.2015; The RNAcentralConsortium 2017). Moreover, in order to determine the possible 
common ancestry of the mir-122 sequence in those species, MEGA X software was employed to generate the phylogenetic tree. The evolutionary history was inferred by using the Maximum Likelihood method and Jukes-Cantor model with Gamma distribution. All positions with less than $95 \%$ site coverage were eliminated, i.e., fewer than $5 \%$ alignment gaps, missing data, and ambiguous bases were allowed at any position (partial deletion option). The tree was replicated with 1,000 bootstraps.

\subsection{Structural Analysis}

\subsubsection{D Structural Analysis}

The earliest step is to determine the conserved 2-D structure for the mir-122 from the representative species with RNAalifold and determine the secondary structure of mir-122 from Tilapia fish with RNAfold (Gruber et al. 2008; Lorenz et al. 2011). The resulted 'dot-bracket notation' data of secondary structure will be utilized for predicting the transition state of the mir-122 stability with Barrier server (Flamm et al. 2002; Wolfinger et al. 2004). Thus, the important step in this part is the elucidation of the siRNA for mir-122 Tilapia with RNAxs (Tafer et al. 2008).

\subsubsection{D Structural Analysis}

Then, the three-dimensional structure prediction of both mir-122 and its siRNA for Tilapia was conducted with modeRNA and simRNA, both of them for generating predictions with homology modeling and $\mathrm{ab}$ initio methods respectively (Magnus et al. 2016; Rother et al. 2011; Magdalena Rother et al. 2011). In this end, after obtaining the protein databank (PDB) file of the models, the HNADock software was utilized to predict the docking possibility of mir-122 Tilapia with its respective siRNA (He et al. 2019). All software was employed by using the default parameters, and the HNADock software has utilized a specific scoring function for RNA-RNA interaction.

\section{Results}

\subsection{Sequence Analysis}

Based upon the retrieved sequences from the RNACENTRAL database, the representative of each species from mammalian, aves, amphibia, and actinopterygii classes is shown in the Table 1.

However, in order to obtain information on the common ancestor of those genes and their clustering, the phylogenetics tree method was devised in Figure
Table 1. The retrieved mir-122 sequences from the representatives species. These are the model species for genome annotation research

\begin{tabular}{ll}
\hline Rnacentral ID & Species \\
\hline URS00006F971C & Mus musculus \\
URS000015B1DD & Bos taurus \\
URS000067AD20 & Danio rerio \\
URS000071B92F & Oreochromis niloticus \\
URS0000914C02 & Xenopus tropicalis \\
URS000065381A & Homo sapiens \\
URS0000646248 & Gallus gallus \\
\hline
\end{tabular}

1. It is expected that the correct tree will eventually provide the correct structural annotations.

The tree shows that, unsurprisingly, the mir-122 of Homo sapiens, Bos Taurus, and Mus musculus are clustered together as the mammalian class. While Xenopus tropicalis and Gallus gallus purposely are in one distinct cluster. It is inferred that the tree is biologically correct because Danio rerio and Tilapia fish are clustered together as part of Actinopterygii class. In this end, as the tree is biologically correct, the sequence annotation could be leveraged to search for the conserved structure of the ncRNA.

\subsection{Structural Analysis}

\subsubsection{D Structural Analysis}

As the phylogenetic tree already validated the biological inference, it is the next logical step to progress further with the structural annotation pipeline. Hence, the following 2D structural conservation alignment was executed in order to comprehend the structure diversity among different organisms. As shown in Figure 2A, the base pair probability is very high, and it shows the plausibility that the structure of all sampled organisms mir122 actually derived from a single entity. Hence, the Tilapia mir-122 structure in Figure 2B closely resembles the conserved structure with only a subtle variation. The calculation of the predicted free energy of the conserved structure is $-54.10 \mathrm{kcal} / \mathrm{mol}$, while the predicted structure of mir-122 Tilapia is -33.30 $\mathrm{kcal} / \mathrm{mol}$

The trajectory of the RNA structures could be elucidated with fine resolution with the barrier server application. The Tilapia mir-122's transition state could be observed in Figure 3. As a standard feature, exactly 10,070,026 structures were predicted by the RNAsubopt applets in the server that formed a way in an energy range of $35.4 \mathrm{kcal} / \mathrm{mol}$ above the minimum free energy. 


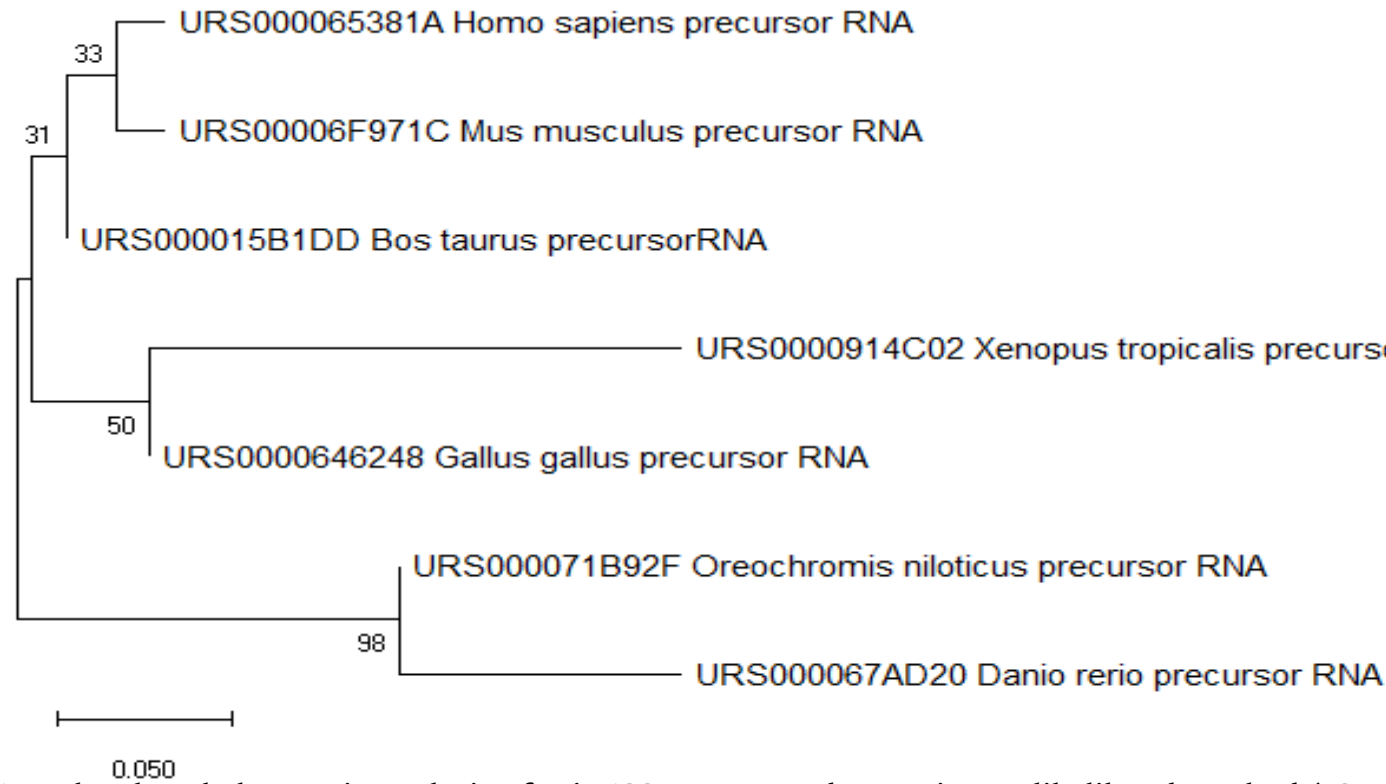

Figure 1. Molecular phylogenetic analysis of mir-122 sequences by maximum likelihood method (JC + G model; 1,000 bootstrap). The number depicts the evolutionary distance between one node and the others. The identifiers of nodes are RNAcentral ID, species name, and RNA identifier

A

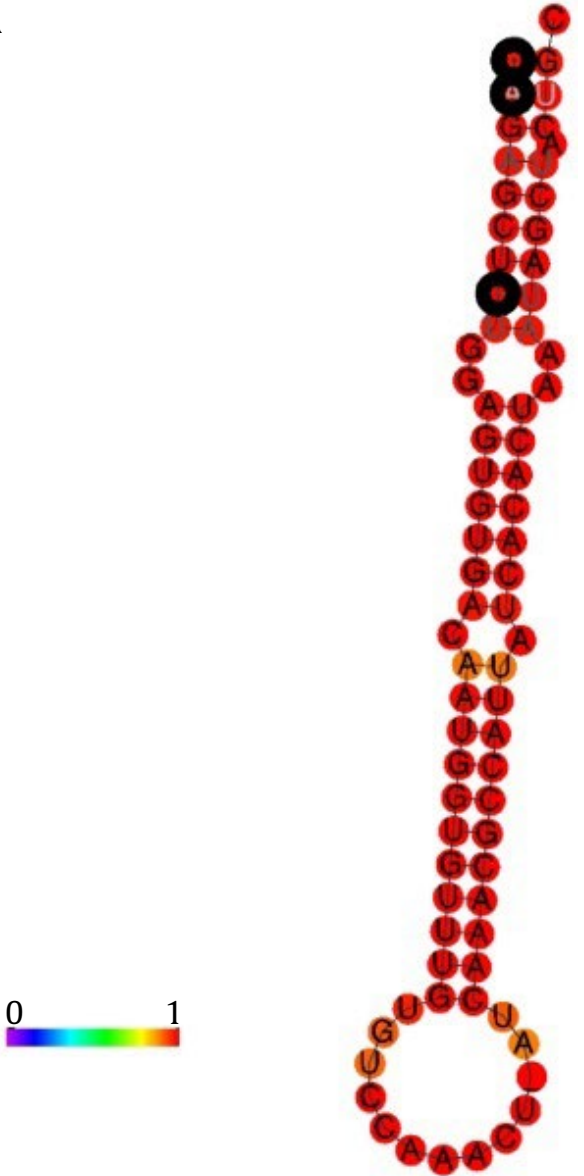

B

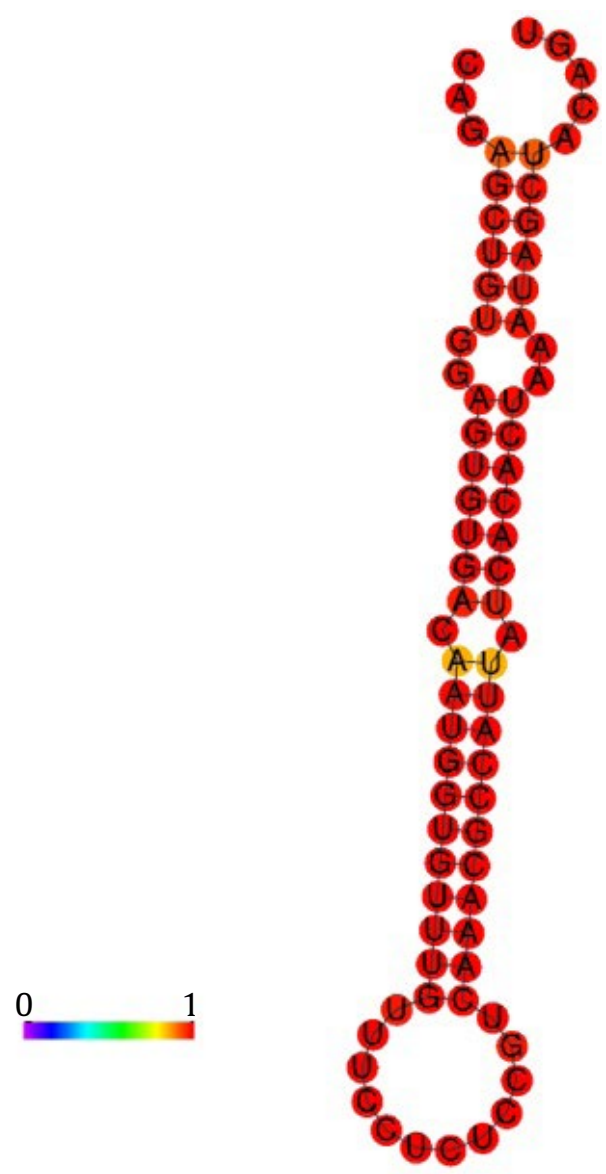

Figure 2. (A) RNAalifold, (B) RNAfold Tilapia. The scale of base-pair probability is using a color legend that starts from probability 0 (dark purple), inferring that the structure is not feasible, and probability 1 (dark red) is the most feasible one. The total domination of the red color in the structures means that the structures are plausible, as the scale inferring to the probability of the structure existence 


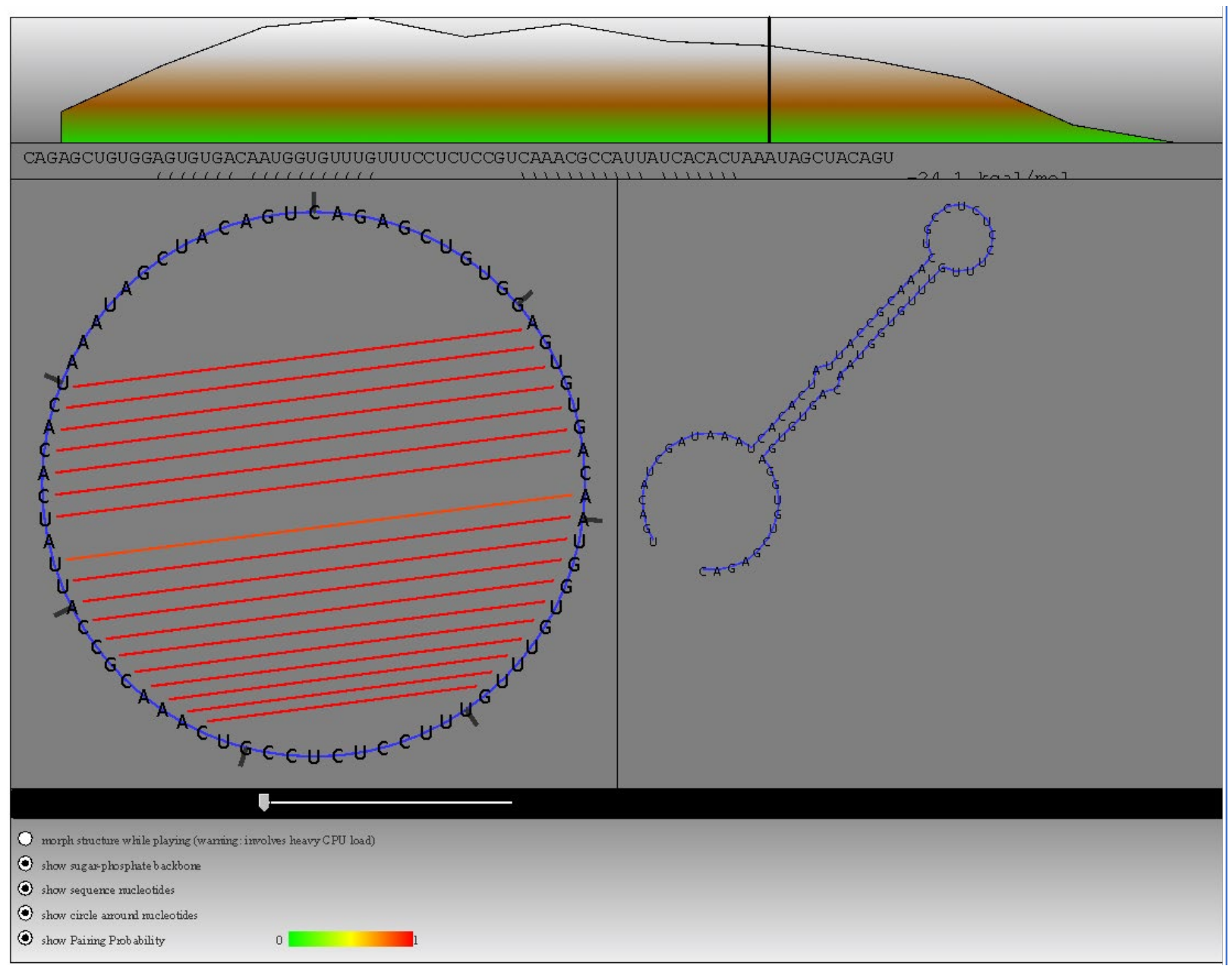

Figure 3. Barrier server annotation of mir-122 Tilapia. The animated picture shows the probability of the structure formation. The circle graph on the left is the graph theory representation of each RNA sequence, while the structure on the right is the predicted structure formation and its designated probability. The left graph will show animated correlated nodes that will be represented in the right graph. Figure in the topmost frame means the free energy depiction. If the mountain plot is higher, it means that the free energy is more negative and more feasible for the structural formation

Figure 4 shows the RNAxs application output of the siRNA that downregulates the mir-122 of Tilapia fish. The taken siRNA is the most favorable design compared with others based on the thermodynamics approach. Thus, the elucidated 2D ncRNA designs are prepared for the next step of the 3D design pipeline.

\subsubsection{D Structural Analysis}

Hence, as shown in Figure 5, the molecular visualization of both the mir-122 and its siRNA could be done in a fine-grained manner. More importantly, the visualization shows that the hydrogen bonds of the RNA molecules could be elucidated. It is an important indicator that the internal structure of the functional groups could sustain the availability of the bonding and proves that there is a high probability if the structures indeed exist. In this end, a more specific molecular simulation method is necessary to examine the interactions of those structures.

The utilized standard for this experiment is the docking between chains $A$ and $B$ of the r(GGUCACAGCCC) 2 crystal structure (PDB ID: 1KD5) shown in Figure 6. Based on the computational validation result, the structure in Figure $6 \mathrm{~A}$ is predicted as the best one due to its existence in the $1^{\text {st }}$ rank among 100 annotated structures in PDB format. Moreover, the $1^{\text {st }}$ rank structure also gives the ligand RMSD $(\AA)$ of 0.60 . Figure 6B shows the top 10 structures superimposed in one Figure. The designated validation method of this research made it clear that the prediction pipeline is actually worked to observe the molecular interaction based on real wet laboratory experiment settings. 


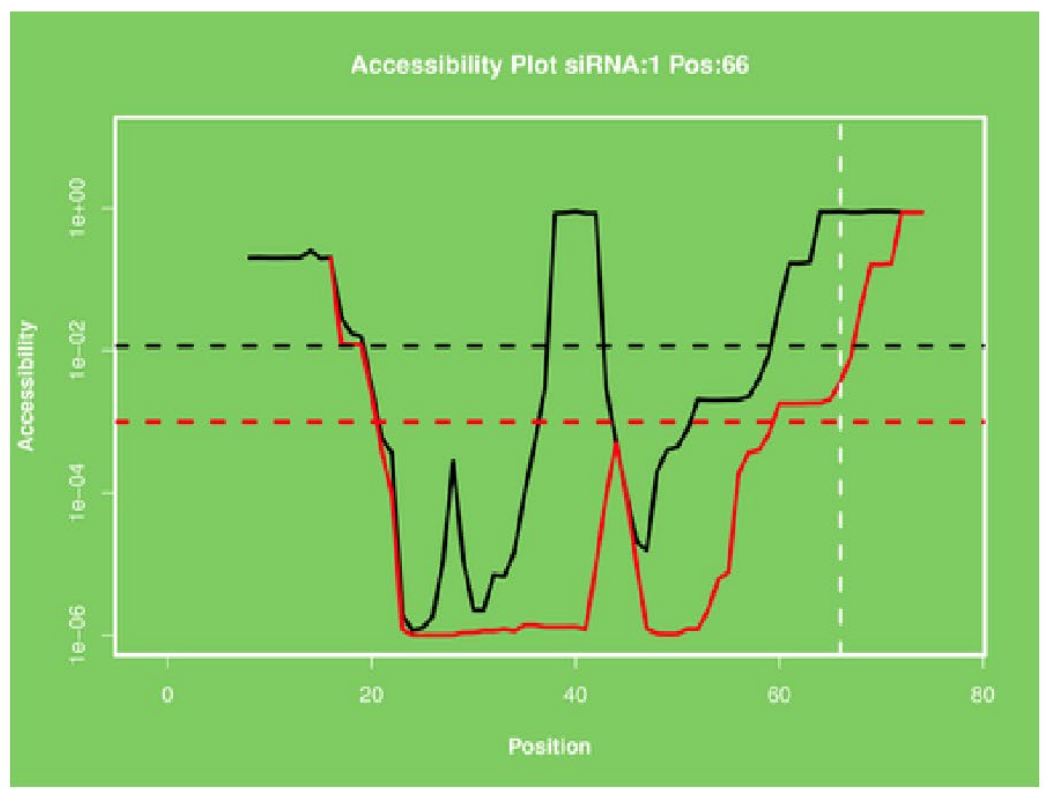

$\begin{array}{lr}\text { siRNA } & 1 \\ \text { Worst Rank } & 2 \\ \text { Position } & 66 \\ \text { Access 8nt } & 0.9071 \\ \text { Access 16nt } & 0.0037 \\ \text { Assymetry (S) } & 1.0000 \\ \text { Assymetry (E) } & 0.9569 \\ \text { Self Folding } & 1.0000 \\ \text { Free End } & 1.0000 \\ \text { Target Seq. } & \text { GCCAUUAUCACACUAAAUA } \\ \text { siRNA Seq. TATTTAGTGTGATAAGGC } \\ \text { BLAST }\end{array}$

Figure 4. The RNAxs output of the mir-122 siRNA. The black plot refers to the accessibility of the target sequence and the red plot refers to the accessibility of siRNA sequence. If approaching zero or touching the base of X-axis, the probability of accessibility for the sequence is zero. If it is farther from zero, the probability will be higher. BLAST iteration could be executed in the low-right of the window to check the homology of the query in the NCBI genbank

A

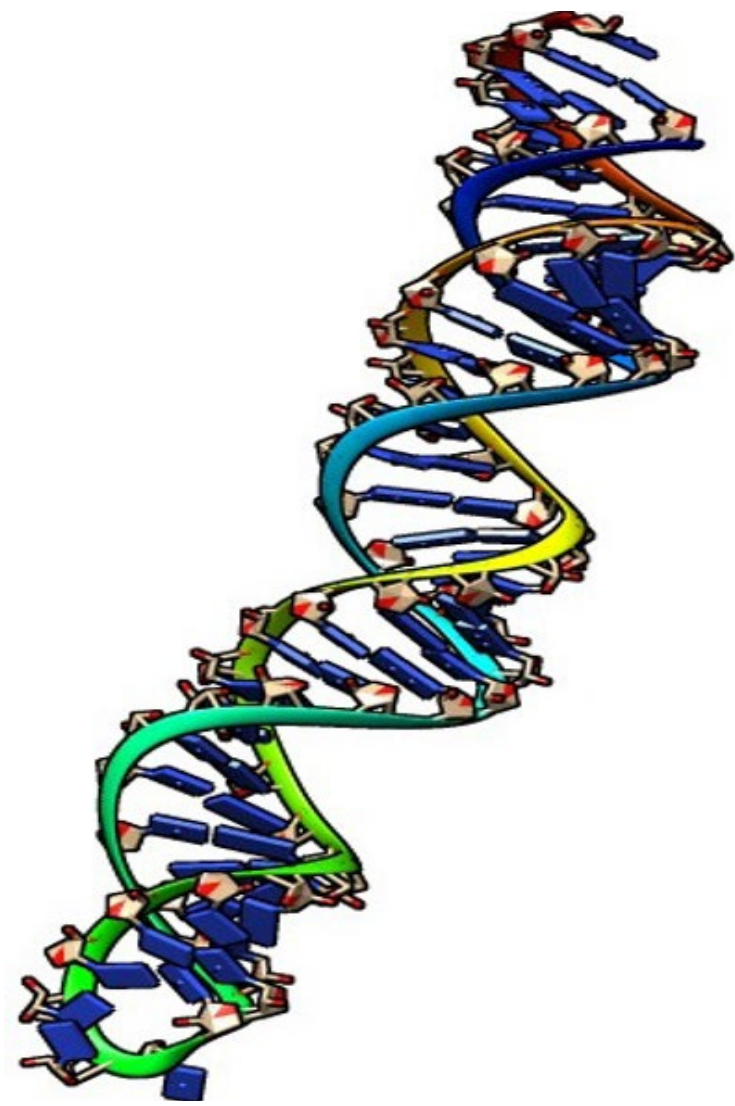

B

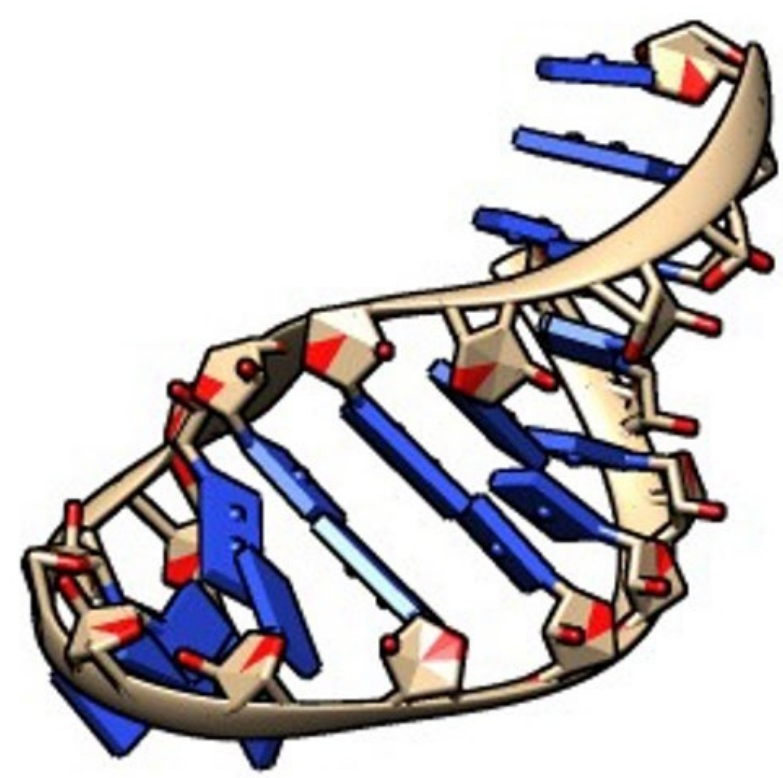

Figure 5. Visualization by UCSF Chimera for the de novo models of (A) mir-122 and (B) siRNA mir-122. The hydrogen bonds that sealed the double-helix structures were depicted in blue planar rectangles. The pentagonal shapes represent the bases 
In this regard, the visualization of the molecular docking result between mir-122 and its respective siRNA could be observed in Figure 7. The docking experiment result will be compared with the validated standard as stated beforehand.
Based on the computational result, the structure in Figure 6A is predicted as the best one due to its existence in the 1st rank among 100 annotated structures in PDB format. Moreover, the $1^{\text {st }}$ rank structure also gives the ligand RMSD $(\AA)$ value
A

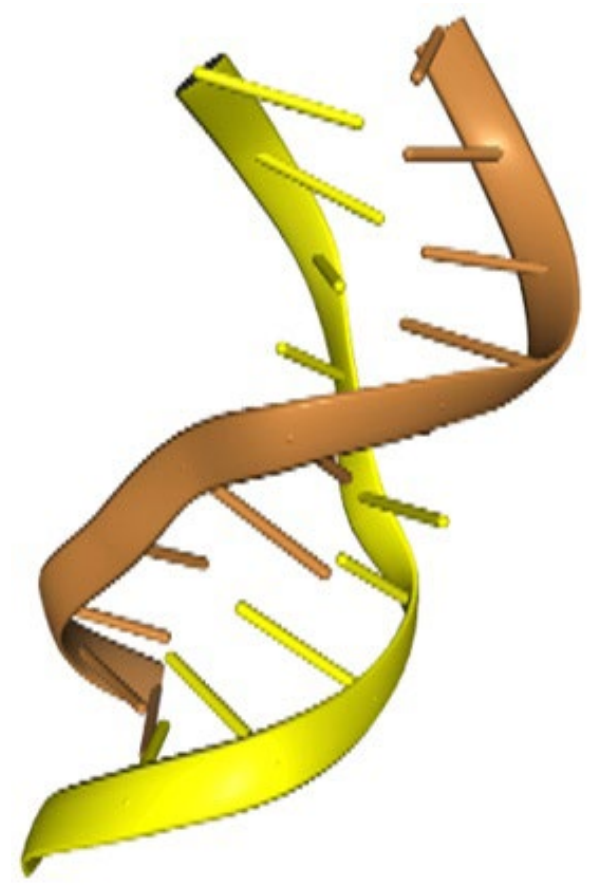

B

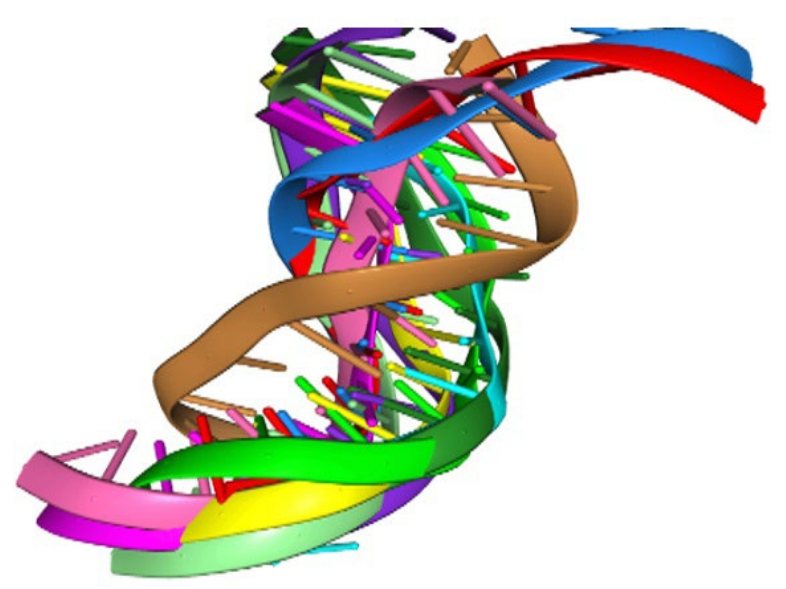

Figure 6. The molecular docking of the crystal structures of r(GGUCACAGCCC)2 (PDB ID: 1KD5) that have already been validated by the wet experiment. The brown-colored RNA is the 1KD5 chain A, while the other colors are the $1 \mathrm{KD} 5$ chain B in different conformations. (A) The best model docking, (B) the 10 best models docking in the cumulative structure

A

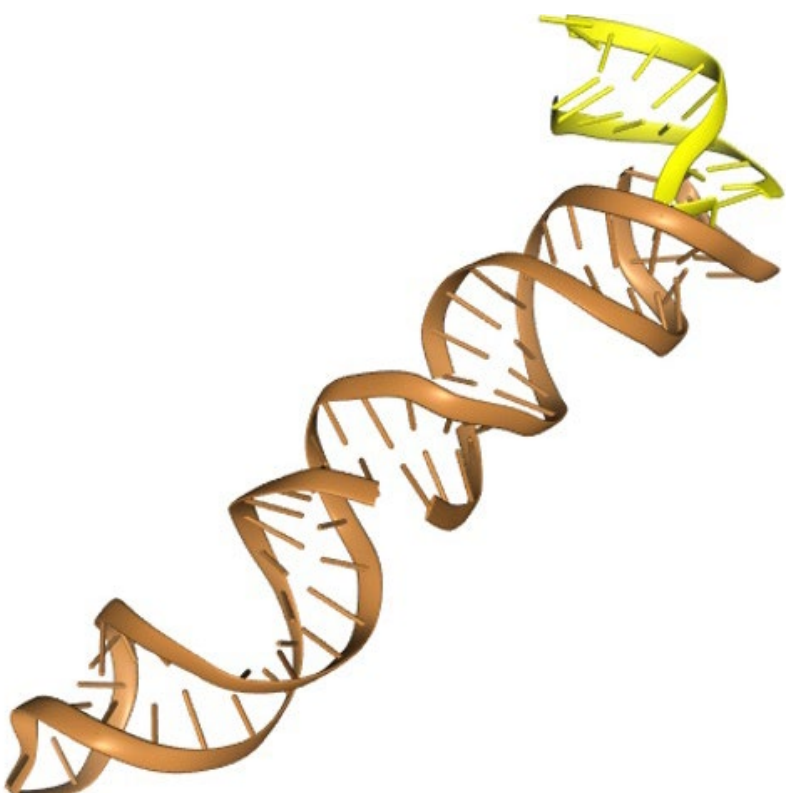

B

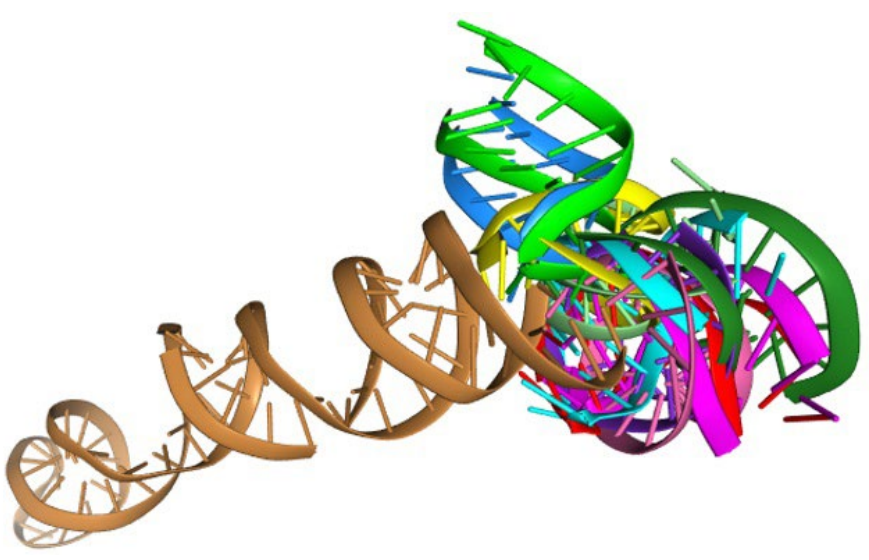

Figure 7. Molecular docking of mir-122 with its respective siRNA. The brown-colored RNA is the mir-122 Tilapia, while the other colors are the siRNA in different conformations (A) the best model docking, (B) the 10 best models docking in the cumulative structures 
of 50.49. Figure 6B shows the top 10 structures superimposed in one Figure. As the ligand RMSD is way above the accepted cut off the $5 \AA$, it is predicted that the binding between the siRNA and mir-122 will not be permanent and prone to be unbound in a very short period of time. However, the docking study implies that the interaction between the mir122 and siRNA is indeed happening. Further studies are needed to observe the implication of the siRNA unbinding in this docking system.

\section{Discussion}

The phylogenetic tree as depicted in Figure 1 is employed because it is necessary to observe whether the biological clustering information of the sequences is in accordance with the established tree in the NCBI taxonomy database (Federhen 2012). The spontaneous values of both structures in the Figure 2 are the strong argument for the feasibility of those structures in nature. Hence, the structural crystallography will eventually be complicated to do (Anderson-Lee et al. 2016).

Hence, as wet laboratory experiment for determining the RNA structure transition is inherently feasible with kinetic isotope effects and single-molecule fluorescence spectroscopy that is not within reach in many laboratories, a more feasible approach is developed for this regard (Chen et al. 2000; Russell et al. 2002; Bartley et al. 2003). Thus, the computational environment is the fittest approach in order to observe this phenomenon. The total amount of structure in the Figure 3 is almost similar to the one that was detected in other experiments with other species and biomarkers (Parikesit 2018c). Hence, it could be inferred that the typical miRNA structures pool could always be detected in a certain amount.

As a plausible approach, silencing mir-122 could be a way to downregulating that transcriptomics biomarker and regulating the fat metabolism (Esau et al. 2006). In this regard, utilization of silencing (si)RNA to silence the mir-122 is a viable option for the down-regulation process (Girard et al. 2008). Based on the homology search in the template of the modeRNA database, the Homology models of mir122 and its siRNA of Tilapia are not found. It suggests that the RNA structure of the mir-122 Tilapia could be considered novel and distinct as it is not similar to any 3D structure in the homology model database
(Figure 4). In this regard, the only method that could be relied on predicting the 3D structure is with the de novo prediction that works by constructing the structure based upon the thermodynamics and kinetics parameters, as depicted in Figure 5 (Das and Baker 2007).

The most viable method to observe the interaction between the RNA molecules is by utilizing molecular docking tools. The docking method is currently very common to observe the interaction between protein-protein, and protein-ligand (Morris and Lim-Wilby 2008). However, until recently, the utilization of this method to comprehend RNA-RNA interaction is not doable due to the unavailability of the scoring function. Hence, the current protocol already provides RNA-RNA scoring function within the HNADOCK application, and the validation of this method is already leveraged by running the structural samples from the wet experiments (He et al. 2019). Based upon the accepted consensus, the RMSD cut-off below 5 A for results in both Figure 6 and 7 is considered a good binding mode (He et al. 2019). The utilized standard for this experiment of the r(GGUCACAGCCC) 2 in the Figure 6 was taken from the wet laboratory experiment. However, the experiment only provided the sequences, and the structure is predicted with our own in-house pipeline.

The application of structural bioinformatics in RNA modeling was previously focused mainly to human biomedical studies. Examples are in the domain of Cancer and infectious disease studies, for devising biomarkers and therapeutics (Agustriawan et al. 2021; Ivan et al. 2021; Parikesit and Nurdiansyah 2020). Comprehensive molecular simulation pipeline for this effort has already been established, albeit with an extensive demand for computational power and specific parameters and scoring functions (Ivan $e t$ al. 2020). Up to now, similar studies for the molecular aspect of the fisheries sciences are considered very limitedand barely exist in the structural bioinformatics community. As the focal point of structural bioinformatics application in humans are to elicit biomedical interests, most of the designs are catered for diagnostics, drugs, and vaccines. Similar demand is very scarce in fisheries studies, except for diagnostics. It is an exception because DNA barcoding in fish is already an established method and is widely deployed in this field (Fitrian and Madduppa 2020; Ayu et al. 2021). However, as the field of agriculture 
and food already embraces the deployment of state-of-the-art bioinformatics tools, the research landscape in this area is beginning to show some significant changes in the structural data curation efforts (Singh et al. 2011; Chasapi et al. 2020).

However, recently the role of structural bioinformatics, especially in the studies of Protein and RNA modeling, is getting stronger in the observation of the molecular aspect of Fisheries sciences (Hauser and Seeb 2008; Dhandare et al. 2020). It is already transcended beyond the frontiers of fish transcriptomics research and entering the realm of 3D biomolecules modeling (Liang et al., 2010; QianXi et al. 2014). Standard methods in molecular simulation such as docking and virtual screening are starting to be gaining ground in this field. In this regard, it remained to be seen what the future of this studies would be because the biomolecules 3D structures of fish in the protein data bank (RCSB) are still scarce if they do not exist (Berman et al. 2013; Rose et al. 2013). Then, many predictions will be catered by the de novo method, and not utilizing existing structures from the wet laboratory with the homology modeling one (Hillisch et al. 2004).

In conclusion, based on the utilized molecular simulation pipeline, the $2 \mathrm{D}$ and $3 \mathrm{D}$ structures of the Tilapia fish mir-122 and its respective siRNA could be predicted in a fine-grained manner. More importantly, with the availability of the RNA-based scoring function, the molecular docking of the mir122 and its designed siRNA could be done and ranked based upon the scoring function. The future venue of this research is to explore the availability of the molecular dynamics method that accommodates the RNA-based scoring function.

\section{Acknowledgements}

The author would like to thank the Research and Community Service Department (LPPM) of the Indonesia International Institute for Life Sciences (i3L) and Research Institute for Fish Breeding (BRPI) for their heartfelt support and providing the facilities for this research. Thanks also goes to Direktorat Riset dan Pengabdian Masyarakat, Direktorat Jenderal Penguatan Riset dan Pengembangan Kementerian Riset, Teknologi dan Pendidikan Tinggi Republik Indonesia for providing Hibah Penelitian Dasar DIKTI/ LLDIKTI III 2019 No. 1/AKM/PNT/2019. Our gratitude also goes to Prof. Rosalba Giugno from the Department of Computer Science, University of Verona, Italy, for providing information on how to leverage the arenaldb database, and Andamar Pradipta, M.A. from the i3L Community Language Center for his excellent proofreading of this manuscript.

\section{References}

Agustriawan, D., Parikesit, arli aditya, Nurdiansyah, R., Ivan, J., Ramanto, K.N., 2021. Correlation and transcriptomic analysis revealing potential microRNA-gene interactions associated with breast cancer formation. Research Journal of Biotechnology. 16, 16-23. https:// doi.org/10.5281/zenodo.4460733

Amaral, P.P., Mattick, J.S., 2008. Noncoding RNA in development. Mammalian Genome. 19, 454-492. https://doi.org/10.1007/s00335-008-9136-7

Amoussou, T.O., Abdou Karim, I.Y., Dayo, G.K., Kareem, N., Toko, I.I., Chikou, A., Toguyéni, A., 2019. An insight into advances in fisheries biology, genetics and genomics of African tilapia species of interest in aquaculture. Aquaculture Reports. 14, 100188. https:// doi.org/10.1016/j.aqrep.2019.100188

Anderson-Lee, J., Fisker, E., Kosaraju, V., Wu, M., Kong, J., Lee, J., ... Das, R., 2016. Principles for predicting RNA secondary structure design difficulty. Journal of Molecular Biology. 428, 748-757. https://doi. org/10.1016/j.jmb.2015.11.013

Anurogo, D., Parikesit, A.A., Ikrar, T., 2019. LncRNAs in CONDBITs perspectives, from genetics towards theranostics. Jurnal Sains Kesihatan Malaysia. 17, 1-16. https://doi.org/10.17576/jskm-2019-1702-01

Ayu, I.P., Wardiatno, Y., Butet, N.A., Madduppa, H. 2021. Review: DNA metabarcoding approach for fisheries management. IOP Conference Series: Earth and Environmental Science. 744, 012005. https://doi. org/10.1088/1755-1315/744/1/012005

Baro, J.A., Hughes, H.C., 1991. The display and animation of full-color images in real time on the macintosh computer. Behavior Research Methods, Instruments, and Computers. 23, 537-545. https://doi.org/10.3758/ BF03209994

Bartley, L.E., Zhuang, X., Das, R., Chu, S., Herschlag, D., 2003. Exploration of the transition state for tertiary structure formation between an RNA helix and a large, structured RNA. Journal of Molecular Biology. 328, 1011-1026. https://doi.org/10.1016/S00222836(03)00272-9

Berman, H.M., Kleywegt, G.J., Nakamura, H., Markley, J.L., 2013. The future of the protein data bank. Biopolymers. 99, 218-222. https://doi.org/10.1002/bip.22132

Bhujel, R.C., Yakupitiyage, A., Turner, W.A., Little, D.C. 2001. Selection of a commercial feed for Nile tilapia (Oreochromis niloticus) broodfish breeding in a hapain-pond system. Aquaculture. 194, 303-314. https:// doi.org/10.1016/S0044-8486(00)00521-4

Bonnici, V., Caro, G.De, Constantino, G., Liuni, S., D’Elia, D., Bombieri, N., ... Giugno, R. 2018. Arena-Idb: a platform to build human non-coding RNA interaction networks. BMC Bioinformatics. 19, 350. https://doi. org/10.1186/s12859-018-2298-8

Boudreau, R.L., Martins, I., Davidson, B.L., 2009. Artificial microRNAs as siRNA shuttles: improved safety as compared to shRNAs in vitro and in vivo. Molecular Therapy. 17, 169-175. https://doi.org/10.1038/ mt.2008.231

Cense, J.M., 1989. MolDraw: molecular graphics for the Macintosh. Tetrahedron Computer Methodology. 2, 6571. https://doi.org/10.1016/0898-5529(89)90030-4 
Chapman, E.J., Prokhnevsky, A.I., Gopinath, K., Dolja, V.V, Carrington, J.C., 2004. Viral RNA silencing suppressors inhibit the microRNA pathway at an intermediate step. Genes and Development. 18, 1179-1186. https:// doi.org/10.1101/gad.1201204

Chasapi, A., Promponas, V.J., Ouzounis, C.A., 2020. The bioinformatics wealth of nations. Bioinformatics. 36, 2963-2965. https://doi.org/10.1093/ BIOINFORMATICS/BTAA132

Chen, J., Fan, Z., Tan, D., Jiang, D., Wang, D., 2018. A review of genetic advances related to sex control and manipulation in Tilapia. Journal of the World Aquaculture Society. 49, 277-291. https://doi. org/10.1111/jwas.12479

Chen, X.Y., Berti, P.J., Schramm, V.L., 2000. Ricin A-chain: kinetic isotope effects and transition state structure with stem-loop RNA. Journal of the American Chemical Society. 122, 1609-1617. https://doi.org/10.1021/ ja992750i

Chi, J.R., 2014. Prolactin I microsatellite as genetic markers for characterization of Five Oreochromis Tilapia species and Two Oreochromis Niloticus strains. Journal of Aquaculture Research and Development. 5, 1-7. https:// doi.org/10.4172/2155-9546.1000251

Chou, K.C., 2004. Structural bioinformatics and its impact to biomedical science. Current Medicinal Chemistry. 11, 2105-2134. Retrieved from http://www.ncbi.nlm. nih.gov/pubmed/15279552

Collí-Dulá, R.C., Martyniuk, C.J., Streets, S., Denslow, N.D., Lehr, R., 2016. Molecular impacts of perfluorinated chemicals (PFASs) in the liver and testis of male largemouth bass (Micropterus salmoides) in Minnesota Lakes. Comparative Biochemistry and Physiology-Part D: Genomics and Proteomics. 19, 129-139. https://doi. org/10.1016/j.cbd.2016.02.001

Das, R., Baker, D., 2007. Automated de novo prediction of native-like RNA tertiary structures. PNAS. 104, 1466414669. https://doi.org/10.1073/pnas.0703836104

De Silva, S.S., Subasinghe, R.P., Bartley, D.M., Lowther, A., 2004. Tilapias as alien aquatics in Asia and the Pacific: a review. FAO. Fisheries Technical Paper. No. 453. FAO, Rome. pp. 65.

Dhandare, B.C., Rather, M.A., Bhosale, B.P., Pawar, R., Guttula, P.K., Pagarkar, A., 2020. Molecular modeling, docking and dynamic simulations of growth hormone receptor (GHR) of Labeo rohita. Journal of Biomolecular Structure and Dynamics. 12, 1-14. https://doi.org/10.1080/0739 1102.2020.1844063

Dong, Z., Chen, Y., 2013. Transcriptomics: advances and approaches. Science China. Life Sciences. 56, 960-967. https://doi.org/10.1007/s11427-013-4557-2

Esau, C., Davis, S., Murray, S.F., Yu, X.X., Pandey, S.K., Pear M., ... Monia, B.P., 2006. miR-122 regulation of lipid metabolism revealed by in vivo antisense targeting. Cell Metabolism. 3, 87-98. https://doi.org/10.1016/j. cmet.2006.01.005

[FAO] Food and Agriculture Organization., 2019a. FAO Fisheries and amp; aquaculture-species fact sheetsOreochromis niloticus (Linnaeus, 1758). Available at: http://www.fao.org/fishery/species/3217/en. [Date accessed: 10 July 2019]

[FAO] Food and Agriculture Organization., 2019b. GLOBEFISH Higlights: a quaterly update on world seafood markets. FAO, 1-72. Available: http://www.fao.org/3/ ca4185en/ca4185en.pdf. [Date accessed: 10 February 2021]

Federhen, S., 2012. The NCBI taxonomy database. Nucleic Acids Research, 40, 136-143. https://doi.org/10.1093/ nar/gkr1178
Fessehaye, Y., El-bialy, Z., Rezk, M.A., Crooijmans, R. Bovenhuis, H., Komen, H., 2006. Mating systems and male reproductive success in Nile tilapia (Oreochromis niloticus) in breeding hapas: a microsatellite analysis. Aquaculture, 256, 148-158. https://doi.org/10.1016/j. aquaculture.2006.02.024

Fitrian, T., Madduppa, H., 2020. Penentuan jenis ikan layang (Decapterus spp.) dengan menggunakan metode analisis morfologi dan DNA barcoding. BAWAL Widya Riset Perikanan Tangkap. 12, 127-135. https://doi. org/10.15578/BAWAL.12.3.2020.127-135

Flamm, C., Hofacker, I.L., Stadler, P.F., Wolfinger, T., Wolfinger, M.T., 2002. Barrier trees of degenerate landscapes. Zeitschrift Für Physikalische Chemie, 216, 155. https:/| doi.org/10.1524/zpch.2002.216.2.155

Girard, M., Jacquemin, E., Munnich, A., Lyonnet, S., and Henrion-Caude, A., 2008. miR-122, a paradigm for the role of microRNAs in the liver. Journal of Hepatology, 48, 648-656. https://doi.org/10.1016/j. jhep.2008.01.019

Griffiths-Jones, S., 2006. miRBase: The MicroRNA Sequence Database. In: MicroRNA Protocols Vol. 342. Humana Press, New Jersey. pp. 129-138. https://doi. org/10.1385/1-59745-123-1:129

Gruber, A.R., Lorenz, R., Bernhart, S.H., Neuböck, R., Hofacker, I.L., 2008. The Vienna RNA websuite. Nucleic Acids Research. 36, 70-74. https://doi.org/10.1093/nar/ gkn188

Hauser, L., Seeb, J.E., 2008. Advances in molecular technology and their impact on fisheries genetics. Fish and Fisheries. 9, 473-486. https://doi.org/10.1111/J.14672979.2008.00306.X

He, J., Wang, J., Tao, H., Xiao, Y., Huang, S.Y., 2019. HNADOCK: a nucleic acid docking server for modeling RNA/ DNA-RNA/DNA 3D complex structures. Nucleic Acids Research. 47, 35-42. https://doi.org/10.1093/ nar/gkz412

Hillisch, A., Pineda, L.F., Hilgenfeld, R., 2004. Utility of homology models in the drug discovery process. Drug Discovery Today. 9, 659-669. https://doi.org/10.1016/ S1359-6446(04)03196-4

Holbrook, S.R., Kim, S., 1997. RNA crystallography. Biopolymers. 44, 3-21. https://doi.org/10.1002/ (SICI)1097-0282(1997)44:1<3::AID-BIP2>3.3.CO;2-B

Ivan, J., Agustriawan, D., Parikesit, A.A., Nurdiansyah, R. 2021. MiRNA-Regulated HspB8 as Potent Biomarkers in Low-Grade Gliomas. Research Journal of Biotechnology, 16, 17-25. https://doi.org/10.5281/zenodo.4460727

Ivan, J., Nurdiansyah, R., Parikesit, A.A., 2020. Computational modeling of AGO-mediated molecular inhibition of ARF6 by miR-145. Indonesian Journal of Biotechnology, 25, 102-108. https://doi.org/10.22146/ijbiotech.55631

KE, A., 2004. Crystallization of RNA and RNA?protein complexes. Methods. 34, 408-414. https://doi. org/10.1016/j.ymeth.2004.03.027

Kozomara, A., Griffiths-Jones, S., 2011. MiRBase: integrating microRNA annotation and deep-sequencing data. Nucleic Acids Research. 39, 152-157. https://doi. org/10.1093/nar/gkq1027

Li, X.H., Wu, J.S., Tang, L.H., Hu, D., 2015. Identification of conserved microRNAS and their target genes in Nile tilapia (Oreochromis niloticus) by bioinformatic analysis. Genetics and Molecular Research. 14, 27852792. https://doi.org/10.4238/2015.March.31.8

Liang, C., Zhang, X., Zou, J., Xu, D., Su, F., Ye, N., 2010. Identification of miRNA from Porphyra yezoensis by high-throughput sequencing and bioinformatics analysis. PLOSONE. 5, e10698. https://doi.org/10.1371/ JOURNAL.PONE.0010698 
Lorenz, R., Bernhart, S.H., Höner zu Siederdissen, C., Tafer, H., Flamm, C., Stadler, P.F., Hofacker, I.L., 2011. ViennaRNA Package 2.0. Algorithms for Molecular Biology. 6, 26. https://doi.org/10.1186/1748-7188-6-26

Magnus, M., Boniecki, M.J., Dawson, W., Bujnicki, J.M., 2016. SimRNAweb: a web server for RNA 3D structure modeling with optional restraints. Nucleic Acids Research,44,279. https://doi.org/10.1093/nar/gkw279

Mattick, J.S., 2005. The functional genomics of noncoding RNA.Science.309, 1527-1528. https://doi.org/10.1126/ science. 1117806

Morris, G.M., Lim-Wilby, M., 2008. Molecular docking. Methods in Molecular Biology. 443, 365-382. https:1/ doi.org/10.1007/978-1-59745-177-2_19

Oliver, A., del Molino, J., Cañellas, M., Clar, A., Bibiloni, A. 2019. VR Macintosh Museum: Case Study of a WebVR Application. Springer, Cham. https://doi. org/10.1007/978-3-030-16184-2_27

Parikesit, A.A., 2018a. Introductory Chapter: The Contribution of Bioinformatics as Blueprint Lead for Drug Design. In: Ivana Glavic, (Eds.), Molecular Insight of Drug Design. InTech, London. pp. 7. https://doi.org/10.5772/ intechopen.79664

Parikesit, A.A., 2018b. Kontribusi aplikasi medis dari ilmu bioinformatika berdasarkan perkembangan pembelajaran mesin (Machine Learning) terbaru. Cermin Dunia Kedokteran. 45, 700-703.

Parikesit, A.A., 2018c. The construction of two-and threedimensional molecular models for the miR-31 and Its silencer as the triple negative breast cancer biomarkers. OnLine Journal of Biological Sciences. 18, 424-431. https://doi.org/10.3844/ojbsci.2018.424.431

Parikesit, A.A., Anurogo, D., 2018. 3D prediction of breast cancer biomarker from the expression pathway of lincrna-ror/Mir-145/Arf6.Jurnal Sains Dan Teknologi. 2, 10-19. Retrieved from https://ojs.uph.edu/index. php/FaSTJST/article/view/1012

Parikesit, A.A., Anurogo, D., Putranto, R.A., 2017. The utilization of bioinformatics in the field of agriculture and health. E-Journal Menara Perkebunan. 85, 105-115. https://doi. org/10.22302/iribb.jur.mp.v85i2.237

Parikesit, A.A., Nurdiansyah, R., 2020. The predicted structure for the anti-sense siRNA of the RNA polymerase enzyme (RdRp) gene of the SARS-CoV-2. BERITA BIOLOGI. 19, 97-108. https://doi.org/10.14203/ beritabiologi.v19i1.3849

Parikesit, A.A., Utomo, D.H., Karimah, N. 2018. Determination of secondary and tertiary structures of cervical cancer IncRNA diagnostic and siRNA therapeutic biomarkers. Indonesian Journal of Biotechnology. 23, 1-6. https:// doi.org/10.22146/ijbiotech.28508

Qiang, J., Tao, Y.F., He, J., Xu, P., Bao, J.W., Sun, Y.L., 2017. miR-122 promotes hepatic antioxidant defense of genetically improved farmed tilapia(GIFT, Oreochromis niloticus) exposed to cadmium by directly targeting a metallothionein gene. Aquatic Toxicology. 182,39-48. https://doi.org/10.1016/j.aquatox.2016.11.009

Qiang, J., Tao, Y.F., Bao, J.W., Chen, D.J., Li, H.X., He, J., Xu, P., 2018. High fat diet -Induced miR-122 regulates lipid metabolism and fat deposition in genetically improved farmed tilapia (GIFT, Oreochromis niloticus) liver. Frontiers in Physiology. 9, 1422. https://doi. org/10.3389/fphys.2018.01422

Qian, X., Ba, Y., Zhuang, Q., Zhong, G., 2014. RNA-Seq Technology and Its Application in Fish Transcriptomics. OMICS: A Journal of Integrative Biology. 18, 98-110. https://doi.org/10.1089/OMI.2013.0110
Reyes, F.E., Garst, A.D., Batey, R.T., 2009. Strategies in RNA Crystallography. Methods in Enzymology. 469, 119-139. https://doi.org/10.1016/S0076-6879(09)69006-6

Rose, P.W., Bi, C., Bluhm, W.F., Christie, C.H., Dimitropoulos, D., Dutta, S., ... Bourne, P.E., 2013. The RCSB protein data bank: new resources for research and education. Nucleic Acids Research, 41, 475-482. https://doi. org/10.1093/nar/gks1200

Rother, M., Milanowska, K., Puton, T., Jeleniewicz, J., Rother, K. Bujnicki, J.M., 2011. ModeRNA server: an online tool for modeling RNA 3D structures. Bioinformatics. 27 2441-2442. https://doi.org/10.1093/bioinformatics/ btr400

Rother, M., Rother, K., Puton, T., Bujnicki, J.M., 2011. ModeRNA: a tool for comparative modeling of RNA 3D structure. Nucleic Acids Research. 39, 4007-4022. https://doi. org/10.1093/nar/gkq1320

Russell, R., Millett, I.S., Tate, M.W., Kwok, L.W., Nakatani, B. Gruner, S.M., ... Pollack, L., 2002. Rapid compaction during RNA folding. Proceedings of the National Academy of Sciences. 99, 4266-4271. https://doi. org/10.1073/pnas.072589599

Singh, V., Singh, A., Chand, R., Kushwaha, C., 2011. Role of bioinformatics in agriculture and sustainable development. International Journal of Bioinformatics Research. 3, 221-226.

Smith, T.J., 1995. MOLView: a program for analyzing and displaying atomic structures on the Macintosh personal computer. Journal of Molecular Graphics. 13, 122-125. https://doi.org/10.1016/02637855(94)00019-O

Speir, M.L., Zweig, A.S., Rosenbloom, K.R., Raney, B.J., Paten, B., Nejad, P., ... Kent, W.J., 2015. The UCSC genome browser database: 2016 update. Nucleic Acids Research, 44, 717-725. https://doi.org/10.1093/nar/gkv1275

Storey, A., 2017. The Basics of Breeding Tilapia for AquaponicsUpstart University. Available at: https://university. upstartfarmers.com/blog/breeding-tilapiaaquaponics. [Date accessed: 11 July 2019]

Tafer, H., Ameres, S.L., Obernosterer, G., Gebeshuber, C.A., Schroeder, R., Martinez, J., Hofacker, I.L., 2008. The impact of target site accessibility on the design of effective siRNAs. Nature Biotechnology, 26, 578-583. https://doi.org/10.1038/nbt1404

The RNAcentral Consortium. 2017. RNAcentral: a comprehensive database of non-coding RNA sequences. Nucleic Acids Research 45, 128-134. https://doi.org/10.1093/nar/gkw1008

Towers, L., 2013. A quick guide to tilapia breeding and farming | The Fish Site. Available at: https://thefishsite.com/ articles/a-quick-guide-to-tilapia-breeding-andfarming. [Date accessed: 11 July 2019]

Ui-Tei, K., 2016. Is the efficiency of RNA silencing evolutionarily regulated?. Int. J. Mol. Sci. 17, 179. https://doi.org/10.3390/ijms17050719

Wolfinger, M.T., Svrcek-Seiler, W.A., Flamm, C., Hofacker, I. L., Stadler, P.F., 2004. Efficient computation of RNA folding dynamics. Journal of Physics A: Mathematical and General.37,4731-4741. https://doi.org/10.1088/0305$4470 / 37 / 17 / 005$ 